\title{
A 'holistic' sonographic view on congenital heart disease - how semiautomatic reconstruction eases the unveiling of abnormal cardiac anatomy part I: right heart anomalies
}

\author{
Jan Weichert ${ }^{1}$ and Alexander Weichert ${ }^{2}$ \\ ${ }^{1}$ University Hospital of Schleswig-Holstein, Campus Luebeck \\ ${ }^{2}$ Charité Universitätsmedizin Berlin Campus Charite Mitte
}

September 21, 2020

\begin{abstract}
Attempting a comprehensive examination of the fetal heart remains challenging for unexperienced operators as it emphasizes the acquisition and documentation of sequential cross-sectional and sagittal views and inevitably results in diminished detection rates of fetuses affected by congenital heart disease. The introduction of three-/four-dimensional spatial-temporal image correlation 3D/4D STIC technology facilitated a volumetric approach for thorough cardiac anatomic evaluation by the acquisition of cardiac 4D datasets by analyzing and correlating numerous images from different heart cycles obtained during an automated sweep and subsequently displaying them in an endless cine loop sequence. However, postanalysis with manipulation and repeated slicing of the volume usually requires experience and in-depth anatomic knowledge, which limits the widespread application of this advanced technique in clinical care and unfortunately leads to the underestimation of its diagnostic value to date. Fetal intelligent navigation echocardiography (FINE), a novel method that automatically generates and displays 9 standard fetal echocardiographic views in normal hearts, has shown to be able to overcome these limitations. Very recent data on the detection of congenital heart defects (CHDs) revealed a sensitivity and specificity of $98 \%$ and $93 \%$, respectively. In this two-part manuscript, we focused on the performance of FINE in delineating abnormal anatomy of typical right and left heart lesions and thereby emphasized the educational potential of this technology for more than just teaching purposes. We further discussed recent findings regarding these morphological changes seen in a pathophysiological and/or functional context.
\end{abstract}

\section{Introduction}

Introduced as a promising tool, volumetry of the fetal heart using spatial-temporal image correlation (STIC) has been shown to enable obtaining in-depth information retrieved from large volume data sets of the fetal heart and proven to be of additional value in offline analysis for multidisciplinary consultation, facilitating a more detailed understanding of the complex fetal anatomy and reducing operator dependency ${ }^{1,2}$. Multiplanar navigation and the application of a number of imaging algorithms are of particular value in evaluation of cardiovascular integrity or function (in combination with color Doppler or M-mode). Nevertheless, quite a number of publications have stated that these techniques have rather poor reliability in clinical practice and have consequently faced limited use despite their widespread availability for more than 15 years $^{3}$. Thus, the major disadvantages of STIC interrogation include the following: professional experience has been shown to be the most limiting factor in the image quality of acquired volumes, and orientation within the volume is cumbersome and remains challenging for most operators, precluding its use in a screening setting ${ }^{4}$. This illustrates the urgent need for a concept to standardize 4D echocardiography and aid targeted navigation in STIC volume data sets. 
In 2013, fetal intelligent navigation echocardiography (FINE) emerged as a novel semiautomatic technique to dissect fetal cardiac anatomy after a STIC volume has been acquired. This intelligent navigation technology is based on manual selection of key anatomical landmarks, allowing the system to automatically realign the volume, reorientate and standardize the anatomical position to find, extract, and display specific diagnostic cardiac planes ${ }^{5}$. Recent studies have demonstrated that the FINE method is able to successfully generate all nine standard views for complete fetal echocardiography in 96-100\% of 2nd and 3rd trimester fetuses. It has also been shown that detection of an altered cardiac morphology in case of congenital heart defects (CHDs) is feasible with high sensitivity $(98 \%)$ and specificity $(93 \%)^{6}$.

In this two-part manuscript, we aimed to scrutinize the advantages of workflow-based semiautomatic postprocessing of STIC volumes for detailed prenatal assessment of cardiovascular anatomy in fetuses affected by congenital heart disease (CHD). Despite the fact that from a physiological perspective left and right ventricular performance are strictly related to that of the other (ventricular interdependence), for teaching purposes, we focused on predominantly right- and left-sided anomalies separately. We highlight the educational value of standardized reconstruction of both cross-sectional and longitudinal cardiac planes in order to aid in establishing correct diagnoses in index cases of normal and anomalous fetal hearts assessed during mid- and third trimester targeted ultrasound.

Detection of congenital heart defects

A recent study on epidemiological data of the potential impact of technology on the diagnosis of congenital malformations demonstrated that mainly the diagnosis of cardiac malformations that were not preferentially present with overt symptoms increased in a 14-year period. The authors suggested that these findings might at least partially be explained by increased screening uptake (and intensity), resulting in improved diagnosis of milder cases of selected common malformations ${ }^{7}$. Although the detection rates of CHD have reportedly increased in national or community-wide regional programs in the last decade ${ }^{8-11}$, the sensitivity still ranges somewhat between $22.5 \%$ and $52.8 \%^{12}$. Local policies, parental sociodemographics, screening access, operator expertise and the type of CHD most likely account for the wide variability in the antenatal diagnosis of $\mathrm{CHD}^{13}$. However, the most striking issue is that the vast majority of CHDs actually occur in the population deemed to be at low risk, and only $10 \%$ of fetal CHD cases occur in pregnancies with known risk factors, such as increased nuchal translucency, family history, or fetal extracardiac malformations ${ }^{14}$. The diagnosis of CHD in this collective clearly shows operator dependency and is directly correlated with the capability of recognizing that the appearance of the heart deviates from normal ${ }^{15}$. This may be related to what Sklansky \& De Vore wrote in their 2016 commentary; i.e., future prenatal cardiac examination and ameliorated detection of altered cardiac anatomy should not only be based on the recommended views and imaging modalities but also on the quality of the clips and the angles at which they are acquired ${ }^{16}$.

A controversial debate exists on which set of cardiac scanning planes should be obtained to screen for CHD. As very recently published, the implementation of extended cardiac views beyond the four-chamber view (4CV) (as shown in figure 1) recommended by the 2014 Consensus Report guidelines for detailed anatomic ultrasound survey led to an increase in examination time and the frequency of both incomplete scans and the rate of repeat examinations ${ }^{17}$. Moreover, the authors stated that detection of CHDs did not improve in their cohort. Similar findings were reported by Sun et al., who could not register any significant change in both referrals and prenatal diagnoses of critical outflow tract anomalies despite revised obstetrical imaging guidelines ${ }^{18}$.

According to a Dutch study addressing the reasons why congenital heart defects are being missed during fetal life, the lack of adaptational skills appears to play an important role in undetected CHDs ${ }^{19}$. It may also require a logical approach to understanding congenital heart disease rather than an approach in which the various lesions are memorized ${ }^{20}$. A prerequisite for this is a standardized display of all cardiac diagnostic planes to capture crucial information on anatomical (spatial) arrangements that will dictate later functional characteristics of the heart. 
Physiology of the right heart

Neglected for many years and even referred to as 'the forgotten chamber', the right ventricle (RV) has proven to be the dominant ventricle in utero ${ }^{21}$. Doppler interrogation has revealed the fetal right ventricular stroke volume to be one-third higher than that of the $\mathrm{LV}^{22}$. There is compelling evidence that right ventricular dysfunction is the major contributor to perinatal mortality even in the setting of left-sided lesions ${ }^{23}$. Recent studies have consistently demonstrated a central role for RV dysfunction in the prognosis and outcomes for a wide variety of acquired and congenital cardiac conditions ${ }^{24}$. In adulthood, the RV differs from the left ventricle in terms of its contraction characteristics at significantly lower myocardial energy costs due to lower impedance of the pulmonary vascular bed accompanied by a unique pressure-volume relationship. In contrast, in the fetus, cardiovascular physiology is characterized by a high-resistance pulmonary circulation; a low-resistance systemic circulation; a large, nonrestrictive ductus arteriosus; right-to-left flow across the foramen ovale; equal pulmonary arterial and aortic pressure; and hypoxemia ${ }^{25}$.

Sonographic imaging of the right ventricle as the most anteriorly situated cardiac cavity in its entirety might be challenging because of the very particular crescentic shape of the right ventricle that wraps around the side $^{26}$. Nevertheless, the apical trabecular architecture including the moderator band that is morphologically maintained in all hearts allows anatomic distinction between right and left ventricles irrespective of the location of the chamber within the ventricular mass. From a physiological perspective, the right and left ventricular free wall thickness and force development are equal throughout fetal life and increase up to 20-fold with advancing pregnancy ${ }^{27}$. The interventricular septum is located on the midline between the ventricular chambers and is flat throughout the cardiac cycle ${ }^{28}$. For comprehensive analysis of congenitally malformed hearts, a tripartite concept of the RV has been established; it is divided into the inlet, apical trabecular and outlet (conus) components ${ }^{29}$. In right-sided CHDs, one or more of these components may be affected, and this will be discussed below.

\section{Ebstein's anomaly}

This right ventricular myopathy was first described by Wilhelm Ebstein in 1866 and is characterized by a failure of tricuspid valve (TV) delamination, annulus dilatation, and highly variable tricuspid valve morphology that typically results in severe tricuspid regurgitation $(\mathrm{TR})^{30,31}$. The frequency of this lesion varies between 1 in 10.000 to 50.000 live births ${ }^{32,33}$. In fact, tricuspid valve dysplasia is an essential part of Ebstein's anomaly (EA). Morphologically, in contrast to isolated dysplasia, the apical displacement of the hinge points of the tricuspid valve in EA is towards the outflow tract with rotation of the valve apparatus along the axis of the aorta, constituting an "all-or-none" criterion for the diagnosis of $\mathrm{EA}^{34}$. The value of the offset distance of the tricuspid septal leaflet compared to that of the mitral valve leaflet for estimation the severity of the disease has been questioned in the past ${ }^{35,36}$. Accordingly, this further highlights the need for an attitudinally appropriate assessment of the deformed and displaced valve. In EA, the aforementioned inlet component of the RV is functionally integrated into the right atrium (atrialized) and may become disproportionately dilated and dyskinetic, whereas the trabecular and outlet portions are situated downstream from the displaced orifice and show preserved contractility ${ }^{37}$. This consequently results in decreased forward blood flow through the right heart.

As has clearly been demonstrated and validated for adult cardiology, fetal 3D echocardiography is able to offer novel insights into the altered morphology and function of the right heart and allows elucidation of all the features of EA (e.g., shape and derangement of the valve leaflets, level of their attachment, and degree of coaptation $)^{38,39}$. Figure 2 shows semiautomatic reconstruction of cardiac diagnostic planes of a fetus at 32 completed gestational weeks. Two-dimensional echocardiography revealed a cardiomegaly, an apically displaced tricuspid valve with marked insufficiency $(>3 \mathrm{~m} / \mathrm{s})$ and a left ventricular outflow tract obstruction (LVOTO). Upon assessment of the semiautomatic reconstructed planes, it could be noted that all nine views reflect anatomic abnormalities corresponding to those frequently seen in EA. Most strikingly, there is a dysplastic TV with displacement of the proximal attachments of its inferior and septal leaflets within the markedly enlarged and left-rotated heart. The atrialized right ventricle (aRV) and its demarcation against the residual RV are clearly depicted in right ventricular outflow tract (RVOT) and ductal arch views. In a 
recent retrospective study, Gottschalk et al. stated that EA was isolated in $54 \%$ of cases and accompanied by other cardiac anomalies in $46 \%$ of cases. Other obstructive lesions of the left ventricular outflow tract were found in two fetuses in their study ${ }^{40}$. In the present case, a concomitant aortic coarctation was noted, which is clearly seen in three cardiac planes (5CV, LVOT and ductal arch views). An abnormal RA/heart index (Celermajer index; > 0.7), cardiomegaly (cardiothoracic circumference ratio $>0.5$ ), TV annulus diameter, TR severity and younger age at prenatal diagnosis and at birth have been shown to be significantly associated with an unfavorable postnatal outcome. Standardized plane reconstruction as shown in figure 2 can ease offline assessment of cardiac dimensions. Absence of antegrade pulmonary blood flow was identified as the most important hemodynamic marker with regard to postnatal survival ${ }^{40-43}$. In a recent multicenter study, qualitative left ventricular dysfunction has been identified as an important predictor of poor postnatal outcome ${ }^{44}$. This functional impairment with reduced left ventricular output is likely secondary to compression by the aRV, warranting close surveillance for LV dysfunction throughout pregnancy $^{44-46}$.

Tricuspid atresia

Tricuspid atresia is a rare congenital heart defect with an estimated prevalence of 1 in 15.000 live births ${ }^{47}$. This lesion was first described by Friedrich Ludwig Kreysig in 1817 and is characterized by an absence of the tricuspid valve, resulting in complete obstruction of blood flow between the right atrium and right ventricle $^{48}$. From a pathophysiologic perspective, the inflow portion of the RV (normally directly related to proper development of the TV) is absent. Consequently, there is an obligatory right-to-left shunt at the atrial level, and a communication between the systemic and the pulmonary circulation is enabled by a perimembranous (or rarely muscular) ventricular septal defect (VSD). In the presence of a large VSD, cardiac remodeling of the trabecular portion is usually less severe, resulting in a larger RV. In those rare cases of TA with an intact ventricular septum, the corresponding ventriculoarterial connection is atretic, and the RV is nonfunctioning and severely hypoplastic ${ }^{49}$. TA is frequently associated with other intracardiac anomalies that dictate the clinical presentation pre- and postnatally. According to the nature of the ventriculoarterial connection, TA has been initially classified into three groups (type I-III); these groups were subsequently modified taking into account the presence and degree of right ventricular outflow tract obstruction ${ }^{50,51}$.

Prenatal diagnosis of TA is usually straightforward, with a high accuracy. Berg et al. noted $46 \%$ discordant ventriculoarterial connections in their cohort. Similar findings were reported in a previous study conducted by Wald and colleagues ${ }^{52}$. Both cases reviewed herein had an atretic TV and ventricular asymmetry but normally arranged great vessels (figure $3 \mathrm{a}, \mathrm{b}$ ) on 2D ultrasound. Doppler interrogation showed no blood flow velocities across the TV. Volume acquisition and subsequent FINE application was performed at 22 gestational weeks in each case and showed an abnormal 4CV with a thickened fibrous plate instead of a competent tricuspid valve. The RV was reduced in size but contractile. The remaining axial planes displayed fundamental differences between both cases. Whereas the ascending aorta in the three-vessel-trachea (3VT) view was s-shaped, the main pulmonary artery was stenotic (figure 3a). The left-sided structures appeared otherwise normal. Pulmonary forward blood flow was maintained through a perimembranous VSD (seen in the $4 \mathrm{CV}$ and LVOT views) and a large interatrial communication. The RVOT plane showed a normal branching of the main pulmonary artery. These anatomic changes are referred to as TA type Ib. Notably, the fetus in figure $3 \mathrm{~b}$ had a completely different hemodynamic situation. In the $3 \mathrm{VT}$ view, there was only one outlet vessel (ascending aorta), and the 4CV view showed a rudimentary RV and an enlarged LA. In addition, the fetus had a restrictive foramen ovale and no communication at the ventricular level. The pulmonary artery was atretic (seen in the RVOT and ductal arch views), corresponding to TA type Ia.

In both studies cited above, the overall survival of pregnancies continued until term was approximately $>80 \%$. The individual prognosis of TA diagnosed in utero was likely to be determined by the presence of associated chromosomal anomalies or syndromes that accompany TA in significant proportion of cases ${ }^{49,52}$. Berg et al. highlighted the need for close surveillance in the third trimester to rule out interatrial restriction and stated that frequently seen DV changes in TA do not indicate cardiac compromise and are rather related to the changes in hemodynamics in affected fetuses ${ }^{49}$. On the other hand, according to a recent study, an 
increased peak velocity index of the DV can be used to predict compromise in fetuses with obstructive right heart lesions ${ }^{53}$.

Pulmonary stenosis

The prevalence of pulmonary stenosis (PS) is estimated to be $6-8$ in 10.000 live births, accounting for $8-10 \%$ of $\mathrm{CHDs}^{54-56}$. Stenosis of the RVOT was first introduced in medical literature by Giovanni B. Morgagni in $1761^{57,58}$ and represents the most common cause of congenital outflow tract obstruction and the second most common CHD postnatally. PS causes a decrease of blood flow from the right ventricle to the pulmonary arteries, subsequently resulting in elevations of right ventricular and pulmonary arterial (proximal to the stenosis) systolic pressure that depend on the severity and distribution of the stenotic part. The level of stenosis may be infravalvular (infundibular), supravalvular or, most frequently, valvular (in $80 \%$ to $90 \%$ of cases due to fusion of the valve commissures). In moderate forms of pulmonary stenosis, the RV morphology can be normal and might escape prenatal diagnosis. In those cases, an increase in flow velocity across the valve is usually the only diagnostic hint. Early diagnosis of PS might be cumbersome because of the diverse spectrum and different course throughout pregnancy ${ }^{54}$. In the absence of RV hypertrophy (decrease in ventricular diastolic compliance and end-diastolic volume), the peak velocity is correlated with the severity of RVOTO ${ }^{59}$. The fetus in figure 3 had moderate cardiomegaly on conventional two-dimensional ultrasound (2DUS), and Doppler interrogation showed turbulent flow across the pulmonary valve and a concomitant tricuspid insufficiency with $>3 \mathrm{~m} / \mathrm{s}$. Standardized analysis using FINE clearly demonstrated moderate cardiomegaly and a narrow RVOT with thickened doming valvular tissue.

A recent cohort study on neonatal outcomes and the need for postnatal pulmonary valvuloplasty revealed that fetuses with mild-to-moderate PS had increased right cardiac output and signs of diastolic dysfunction with a higher ductus venosus pulsatility index. Fetuses that needed cardiac intervention were found to have significantly smaller and more hypertrophic RVs and pulmonary valve diameters and reduced tricuspid annular-plane systolic excursion (TAPSE) ${ }^{56}$. Mild-to-moderate cases of PS carry a favorable prognosis. Nevertheless, the thin wall of the RV makes it sensitive to alterations in the pulmonary artery pressure. With ongoing pregnancy, PS may worsen and result in severe PS (figure 4) that may even progress to pulmonary atresia. Due to the chronic increase in afterload, the RV dilates and develops muscular hypertrophy ${ }^{60}$. The tricuspid annulus might also dilate, causing severe tricuspid regurgitation (as shown in figure 4), which may subsequently lead to severe right heart failure.

Pulmonary atresia with an intact ventricular septum

Pulmonary atresia with an intact ventricular septum (PAIVS) constitutes a rare cardiac condition with a reported frequency of 1 in 22.000 pregnancies that accounts for approximately 2-3\% of all CHDs prenatally ${ }^{61}$. Although progression of severe PS and subsequent development of PAIVS during fetal life have been documented, studies on cardiac morphogenesis have suggested that this anomaly might occur shortly after cardiac septation. In contrast, pulmonary atresia with a ventricular septal defect (PAVSD) - also classified as a complex variant of tetralogy of Fallot - evolves shortly after partitioning of the conotruncus before closure of the ventricular septum ${ }^{62,63}$. Nevertheless, the exact pathomechanisms of PAIVS are not well understood to date. This may also be related to the striking heterogeneity of the size and physiology of the RV, the morphology of the tricuspid valve, the degree of valvular insufficiency and the presence of ventriculocoronary connections (VCCs)/fistulae. These morphological features dictate classification into Type I-III PAIVS. The pulmonary valve is usually imperforate, the ventricular septum is intact, and the pulmonary blood flow is maintained by a retrograde filling via a patent ductus arteriosus. In the vast majority of cases, the cardiac dimensions have changed into a massively enlarged heart with a hugely dilated right atrium due to retrograde jet across the insufficient TV, as displayed in figure 5 (wall-to-wall heart). This condition can subsequently lead to relevant compression of the lungs.

For further delineation of the disease with regard to postnatal outcomes, different scoring systems based on different predictive echocardiographic markers have been introduced ${ }^{61,64}$. A very recent retrospective cohort study revealed that cardiac parameters such as the RV-to-LV length ratio [?] $0.6, \mathrm{TR}<2 \mathrm{~m} / \mathrm{s}$, and the 
presence of VCCs were significantly associated with a univentricular postnatal outcome ${ }^{62}$. The semiautomatic approach allows exact alignment of the cardiac diagnostic planes and precise calculation/assessment of predictive markers. The heart assessed in figure 5 had severe tricuspid regurgitation and no signs of ventriculoarterial circulation, which is in line with previous reports ${ }^{65}$.

Double outlet right ventricle

Double outlet right ventricle (DORV) refers to a complex diagnostic entity that commonly occurs as part of a range of heterogeneous cardiac defects. Although early reports date back to the 18th century, the first detailed descriptions of the clinical appearance of a large range of anatomical variations were written later ${ }^{66}$. In 1949, Taussig and Bing reported on a case of a transposed aorta and pulmonary trunk that both originated from the right ventricle ${ }^{67}$. Subsequently, this anomaly and accompanying defects have been further characterized with the spatial relationship of the VSD to the semilunar valves of the great arteries and the presence and extension of the outflow tract obstruction, building the morphological basis for the most widely used clinical classification ${ }^{68-72}$. Embryologically, DORV is supposed to represent a relatively primitive cardiac condition with failed conotruncal rotation and a leftward shift of either the aortic or pulmonary conus. The precise mechanisms by which specific genetic lesions or teratogenic exposures result in maldevelopment from normal anatomy to DORV phenotypes remain unknown and may underscore etiologic heterogeneity. Although DORV constitutes a conotruncal anomaly estimated to occur in $0.03-0.07$ of 1,000 live births, this spectrum of anomalies is committed to the RV, and its physiology and will be discussed below. Notably, the frequency of double outlet left ventricle (DOLV) seems to be significantly lower than that of DORV. As a conotruncal anomaly, it is described to have similar anatomic features to those observed in DORV; these include features of a variety of entities ranging from a simple large VSD to TOF and complete TGA.

According to the consensus definition made by the Congenital Heart Surgery Nomenclature and Database Project, four major anatomic types have been proposed that merely rely on the relationship of the ascending aorta to the pulmonary artery (PA) at the level of the semilunar valves ${ }^{71}$. These types include (1) right lateral aorta to the PA as the most common condition in DORV (side-by-side relationship); (2) right anterior aorta (d-transposition type); (3) right posterior aorta (ToF type); and (4) left anterior aorta (ltransposition type). With respect to the location of the VSD (subaortic as the most frequent type followed by subpulmonary, doubly committed or noncommitted) and given that there is AV concordance, up to 16 variations of DORV may be found. Even more variants of DORV are possible in case of situs ambiguous and/or an intact interventricular septum. However, from a surgical perspective, based on the clinical presentation, a functional classification scheme has been introduced that considers four general types of DORV - VSD-type (DORV with normally arranged vessels and a subaortic or doubly committed VSD);Fallot-type (DORV with a subaortic or doubly committed VSD and RVOTO); TGA-type (Taussig-Bing, DORV with a subpulmonary VSD but usually no RVOTO); and noncommitted VSD-type (DORV with a remote VSD and possible RVOTO). Recently, a fifth type referred to as AVSD-type (DORV with AVSD/heterotaxy) has been proposed $^{73}$. In a recent series by Gottschalk et al., the accuracy of prenatal diagnosis taking into account all the anatomic details of DORV was $92 \%$, which was in line with previous studies ${ }^{74-76}$. In their study, all fetuses had additional cardiac anomalies, including severe RVOTO and LVOTO, HLV, partial or total anomalous pulmonary venous connection or coronary anomalies, which, when present, may commonly lead to an abnormal $4 \mathrm{CV}$ view, as exemplified in figure 5. The frequency of extracardiac anomalies ranges between 19 and $73 \%$, and additional chromosomal defects are found in 12 to $45 \%$ of cases in current literature ${ }^{70,74-78}$.

A number of case series have stated that ascertaining an antenatal diagnosis of DORV continues to be difficult given the pronounced anatomic variability as this cardiac defect may share morphological similarities with either tetralogy of Fallot (ToF) or transposition of the great arteries, as stated below ${ }^{74,78}$. Moreover, during grayscale US, the four-chamber view is usually normal, and, on the other hand, the exact position of the accompanying VSD defining the subtypes of DORV may be hard to characterize. Detailed anatomic evaluation tends to be more accurate in fetuses with biventricular anatomy than in those with single-ventricle hearts ${ }^{74}$. The challenge of antenatal evaluation is to elaborate the exact course, size and relation of both great arteries and to distinguish a genuine double outlet situation from classical ToF and or TGA. Due 
to the malposition of the great arteries, only a single vessel (typically the aorta) may be noticed when imaging the $3 \mathrm{VT}$ view, while angling the US probe can allow visualization of the parallel arrangement of both outlet vessels (even when the aorta is right posterior to the PA). In this regard, Zidere et al. reported on the enhancement of visualization of cardiac anatomy using $3 \mathrm{D}$ reconstruction that led to the accurate categorization of the morphological type and prediction of surgical repair ${ }^{79}$. As illustrated in figure 6 a-d, a standardized reconstruction of both axial and sagittal views of fetal hearts with DORV enables a more detailed assessment of the malpositioned vessels and gives valid inferences regarding the most likely anatomic subset of the disease.

Although the majority of cases of misdiagnosed DORV were shown to have a final diagnosis within the same spectrum of disease, the morphologic subtype, irrespective of pre- or postnatal diagnosis, is a major determinant of the outcome ${ }^{74,80}$. Notably, only a few studies correlated their antenatal diagnostic accuracy with the prediction of the expected postnatal surgical approach, namely, the need for uni- or biventricular repair. According to Lacour-Gayet et al., intracardiac repair of DORV, in the case of two viable ventricles, can currently be achieved in nearly all anatomical subtypes including DORV-nc-VSD and DORV-AVSDheterotaxy $^{73}$. Nevertheless, DORV, even without heterotaxy, is associated with complex postnatal care and a high risk of early demise.

Tetralogy of Fallot

Tetralogy of Fallot (ToF) is one of the most common cyanotic heart defects with an incidence of 3-5 per 10,000 live births, accounting for approximately 7-10\% of congenital heart defects in liveborn children ${ }^{81}$. Historically, the underlying anatomic condition was attributed to Etienne-Louis Fallot in 1888, who introduced the term 'La Maladie Bleue', the Blue Disease ${ }^{82,83}$. However, it was the merit of the Danish anatomist Niels Stenson, who described this pathology during a necropsy of a malformed fetus with ectopia cordis already in $1671^{84}$. In 1924, Maude Abbott coined the term 'Tetralogy of Fallot', as Fallot was the first to link the defining classical clinical features: RV outflow tract obstruction (RVOTO), ventricular septal defect, overriding aorta, and right ventricular hypertrophy.

Embryologically, anterocephalad deviation of the developing outlet ventricular septum together with hypertrophy of septoparietal trabeculations determine both the RV outflow tract obstruction and the malaligned ventricular septal defect with an overriding aorta ${ }^{81}$. The exact cause of this combination of lesions remains unknown, and its etiology is thought to be multifactorial including both environmental and genetic factors. The reported incidence of chromosomal anomalies in ToF is $29 \%$ (including microdeletion of 22q11.2). According to a recent systematic review, 22q11.2 microdeletion is apparently three times more common in ToF with PA. Notably, aneuploidies are more often in classical $\mathrm{ToF}^{85}$. Other concomitant cardiac anomalies comprise an atrioventricular septal defect (AVSD), a right-sided aortic arch (RAA), an anomalous origin of the coronary arteries, a left persistent superior vena cava and total anomalous pulmonary venous return (TAPVR). In subset of cases, ToF is complicated by a severely underdeveloped or even absent pulmonary valve that is replaced by a thickened infundibulum and rudimentary valve tissue at the level of the pulmonary valve annulus, with usually massively dilatated pulmonary arteries, as stated below.

In clinical practice, there is a broad spectrum of this condition. The most common variety of ToF consists of a mild-to-moderate RVOTO and normally sized branch pulmonary arteries. In utero, RV hypertrophy is almost always absent as the pressure gradient between of right and left ventricles is rather low, and the four-chamber cardiac view appears to be normal. On the other hand, there may also be complete obstruction of the RVOT, which is similar to pulmonary atresia with VSD. The pulmonary blood flow in this case is maintained from the aorta either retrogradely via the ductus arteriosus supplying the PAs or via major aortopulmonary collateral arteries (MAPCAs). In figure 7, the cardiac anatomic changes in a fetus with ToF/PS are illustrated. Notably, the $3 \mathrm{VT}$ and $4 \mathrm{CV}$ views are normal including the cardiac axis, and the DA is patent, as in 80-90\% of all ToF cases. A perimembraneous VSD is clearly seen in the $5 \mathrm{CV}$ and LVOT views with an overriding aorta. The main pulmonary artery is slightly smaller (than the ascending aorta) in the RVOT and ductal arch views. Additional color Doppler interrogation revealed laminar, nonturbulent flow across the PV, precluding a hemodynamically significant RVOTO. Yeo and Romero published a report of a 
case of ToF/PA analyzed with the FINE method and clearly demonstrated a narrow and atretic RVOT $^{86}$. It has previously been shown that an abnormal cardiac axis in fetuses with ToF is highly predictive of the presence of pulmonary atresia and a right-sided aortic arch and is linked to postnatal death ${ }^{87}$. In this regard, a recent study on the prevalence of genetic abnormalities supported the impact of cardiac angle assessment as levorotation of the cardiac axis was noticed in two-third of ToF cases with genetic anomalies (assessed by chromosomal microarray analysis $)^{88}$. Lv et al. published on a big data analysis for the differential diagnoses of ToF; based on their results, the PA/Ao ratio constitutes the primary parameter to distinguish ToF from large malalignment VSD, which is in line with observations by Wu and colleagues, who calculated 11 different cardiovascular dimensions applied on STIC volumes and were able to show that all fetuses with ToF had abnormal Ao z-scores and reduced PA/Ao ratios ${ }^{89,90}$. A recent multicenter study confirmed these parameters to be the most valid predictors of neonatal intervention (PV:AoV ratio <0.6, PV:AoV z-score difference [?]5) ${ }^{91}$.

Absent pulmonary valve syndrome

Absent pulmonary valve syndrome (APVS) is characterized by the combination of an absent or hypoplastic pulmonary valve, stenosis of the pulmonary valve annulus, and aneurysmal dilatation of the pulmonary trunk and its branches. APVS accounts for 10-20\% of all ToF cases prenatally, whereas the incidence in postnatal series is estimated to be significantly lower, ranging between 3 to $6 \%$ of all ToF cases and 0.2 to $0.4 \%$ of all CHDs. It was first described by J. Crampton during an autopsy of a 10-year-old boy who died from a severe heart failure in $1830^{92}$. This case was further delineated by N. Chevers in $1846^{93,94}$.

According to current literature, this lesion is categorized into three subtypes: (I) the predominant type with an absent pulmonary valve, a ventricular septal defect and an overriding ascending aorta. It is considered an extreme variant of tetralogy of Fallot (Fallot type APVS; ToFAPV), also referred to as Miller-Lev-Paul syndrome in postnatal series ${ }^{95}$. In the vast majority of cases, the ductus arteriosus (DA) is absent. In addition, two very rare variants including (II) APVS with an intact ventricular septum (IVS) and a patent DA (non-Fallot type APVS) and (III) APVS with an intact ventricular septum and concomitant tricuspid atresia have been described to date. There is a reported association of ToFAPV with a microdeletion of 22q11.2 (21-25\%) and trisomy 13 and 18 ${ }^{96,97}$. In two recent larger prenatal series that both included first trimester cases, the incidence of ToFAPV was up to 6 times higher than that of APV and IVS (83.1-92.5\% vs. 7.5-16.9\% ${ }^{98,99}$. Notably, all fetuses diagnosed in early pregnancy had a patent DA, and none of them survived beyond 24 gestational weeks due to progressive hydrops or other lethal conditions, which is in line with prior reports. Berg et al. hypothesized that agenesis of the ductus arteriosus is essential for primary fetal survival in fetuses with TOF and APVS; otherwise, the enormous diastolic volume overload caused by the regurgitant flow from the aorta through the patent arterial duct will subsequently lead to early intrauterine demise $^{100}$. Dilated main and branch pulmonary arteries might result from elevated pressure and volume loading rather than from connective tissue defects and can exert pressure on the surrounding respiratory system (potentially causing obstructive emphysema, atelectasis and tracheobronchomalacia ${ }^{101}$ ). However, the real clinical impact of these findings is not fully understood nor are there significant predictors of neonatal respiratory distress as quantification of echocardiographic variables, including the pulmonary valve annulus, right pulmonary artery diameter and cardiomegaly, were not linked with an unfavorable outcome ${ }^{99}$.

Figure 8 shows the above discussed hallmarks of APVS in a fetus at 27 weeks as a marked leftward rotation of the cardiac axis, as recently reported in the study by Axt-Fliedner et al. ( $88 \%$ abnormal cardiac axis) ${ }^{98}$. The DA is apparently absent, but, most obviously, there is huge bulging of the main and branching pulmonary arteries. The proximity to vascular and tracheal structures is clearly depicted. The value of conventional $3 \mathrm{D}$ reconstruction with color doppler interrogation has previously been shown ${ }^{102}$. However, to capture the entire pathology of APVS, a detailed reconstruction of all 9 planes using FINE technology that gives an excellent overview of the malformed anatomy is helpful.

Conclusions 
The ongoing diagnostic dilemma of CHDs being the most common group of malformations affecting fetuses and newborns and the varying detection rates of CHDs in the general population merits consideration as the prenatal screening for CHDs remains flawed ${ }^{16}$. The clinical relevance of this issue is obvious considering that an estimated $60 \%$ of newborns with CHDs will require a corrective intervention throughout their lives. Fifty percent of affected newborns need an intervention in their first year of life, among whom two-thirds are characterized as being critical regarding short-term morbidity and mortality $(20 \% \text { of all CHDs })^{20}$. Moreover, CHDs diagnosed postnatally result in greater costs merely related to emergency transportation of ill infants ${ }^{103}$. Despite the adoption of updated screening guidelines, the implementation of series of diagnostic planes to visualize cardiac anatomy, 2-dimensional echocardiography shows limitations related to image acquisition, angle dependency and, most strikingly, operator experience.

The advantages of 3D/4D echocardiography (STIC) over conventional 2D ultrasound in delineating cardiac anatomy have been clearly elaborated. Being less operator-dependent, it allows for more reproducible and objective echocardiographic assessment of the fetal cardiac morphology and function of all chambers and valves. However, a number of publications have argued that the additional value of $3 \mathrm{D} / 4 \mathrm{D}$ US in the prenatal diagnosis of CHDs is rather limited and has only been reported in centers with high expertise as it requires extra time and effort ${ }^{1,104-106}$. Since the introduction of a semiautomatic technology (FINE), a standardized volumetric approach for cardiac anatomic assessment has become available to overcome the limitations of effective performance of fetal cardiac examination. FINE has recently been shown to enable cardiac evaluation in normal and CHD-affected fetuses with both high specificity and sensitivity ${ }^{6}$.

We demonstrated the superior value of this approach to comprehensively assess altered cardiac anatomy. It has previously been shown that the acquisition plane and insonation angle are crucial for both $2 \mathrm{D}$ image quality and proper volume computing ${ }^{107}$. It is of note and illustrated herein that the use of standardized procedures, namely, automatically realigned cardiac planes facilitate a systematic evaluation of the fetal heart virtually irrespective of fetal position. FINE provides the opportunity for even unexperienced operators to become familiar with the anatomy of the fetal heart and the spatial relationships of the heart structures. From our perspective, it seems logical as a next step that 4DUS with subsequent FINE application could be incorporated in daily practice in the future. However, using such technology to examine the fetal heart requires an important prerequisite, i.e., structured training interventions and feedback for sonologists to acquire high-quality volume data sets so that they are informative ${ }^{15,108,109}$.

Figures

Fig. 1: Four-chamber views of different fetal conditions. Panel a shows normal fetal anatomy, whereas panels $\mathrm{b}$ to $\mathrm{f}$ depict cardiac anomalies, which will be discussed and further delineated within the paper.

Fig. 2: Ebstein's anomaly at 32 completed weeks with STIC volume reconstruction and automatic labeling using FINE method. All nine diagnostic planes are clearly depicted. The 3-vessel-trachea view shows a size discrepancy of the great vessels with a small transverse aorta. The 4-chamber view is abnormal with a marked left rotation (63 degrees) and ventricular asymmetry $(\mathrm{LV}<\mathrm{RV})$ and demonstrates apically displaced tricuspid valve hinges (atrialization of the RV; aRV) with somewhat thickened septal and lateral leaflets. In both the 5-chamber view $(5 \mathrm{CV})$ and left ventricular outflow tract (LVOT) views, there is a small ascending aorta corresponding to tubular aortic stenosis. The RVOT view shows normal main and right branch pulmonary arteries and aRV. There is no regularly filled stomach in the abdominal plane. The ductal arch view depicts the rotated tricuspid valve and gives an impression of the remaining genuine RV. In contrast, the aortic arch is rather hypoplastic, which confirms the finding of an obstructed LVOT. In addition, an enlarged RA can be seen. The vena cave view denotes similar findings.

A - transverse aortic arch; Ao - aorta; Desc - descending; IVC - inferior vena cava; LA - left atrium; LV left ventricle; P - pulmonary artery; PA - pulmonary artery; RA - right atrium; RV - right ventricle; RVOT - right ventricular outflow tract; S - superior vena cava; SVC - superior vena cava; Trans - transverse.

Fig. 3: Tricuspid atresia at 22 gestational weeks. FINE application on STIC volumes in both cases showed hypoplastic right-sided cardiac structures. While assessing the altered anatomy in detail, subtle but func- 
tional important differences can be noted. Whereas the 3VT view in the left panel (a) demonstrates an only slightly smaller main pulmonary artery, there is a hardly a visible pulmonary arm in panel b, corresponding to a severely hypoplastic or atretic RV outflow. The RV in panel b is small and hypocontractile due to an obstructed inflow via the atretic TV. The findings are referred to as hypoplastic right heart (in contrast to the typical findings of tricuspid atresia shown in panel a). A perimembranous VSD was seen in the 4CV, $5 \mathrm{CV}$ and LVOT views (panel a); this interventricular communication could only be assumed in the 4CV view (panel b). There was a normal interatrial communication via a patent foramen ovale. The ductal arch view in panels $a$ and $b$ is abnormally thin. The LVOT as well as the aortic arch in both cases are normal.

Fig. 4: Severe pulmonary stenosis seen at 29 weeks. Diagnostic plane reconstruction using FINE shows moderate cardiomegaly and a slight left-rotated cardiac axis. The main pulmonary artery depicted in the $3 \mathrm{VT}$ view is narrow due to a thickened pulmonary valve $(\mathrm{PV})$. There is a moderate asymmetry in ventricular and atrial size, and the tricuspid valve leaflets appear to be thickened (related to marked regurgitation confirmed by additional Doppler interrogation). The RV cavity is narrow but shows myocardial hypertrophy. The LVOT is otherwise normal; on the other hand, the RVOT shows an hourglass-like appearance with an echoic, thickened PV corresponding to valvular stenosis. Both arch views as well as the bicaval plane are normal.

Fig. 5: Fetus with critical pulmonary stenosis and an intact ventricular septum at 33 weeks (panel a) and complex cardiac anomaly with pulmonary atresia and an intact ventricular septum, tricuspid atresia, LVOTO and pericardial effusion at 17 weeks (panel b). In both cases, there is a marked cardiomegaly in late and early pregnancy caused by a significant RVOT obstruction. The characterizing anatomic sequelae of RVOTO are clearly depicted after reconstruction using FINE. The 3VT view in both cases is abnormal. In panel a, both vessels are equal in size, and the PV is thickened and domed through cardiac cycle. In panel $\mathrm{b}$, the pulmonary artery cannot be visualized, resulting in an 'I'-shaped appearance on the 3VT view. The entire cardiac morphology is distorted, and the cardiac axis is left-rotated. In panel a, the massively enlarged heart occupies more than half of the thorax (merely due to the dilated RA) and extends from wall to wall. The RV is round, and the myocardium shows marked hypertrophy. The TV leaflets appear dysplastic and thickened (Doppler ultrasound revealed regurgitation of $>2 \mathrm{~m} / \mathrm{s}$ ). In panel $\mathrm{b}$, the TV is atretic, the LV is normal, and the MV is patent. The RVOT plane confirms the narrow pulmonary trunk that bifurcates into the pulmonary arteries (panel a), and no detectable pulmonary artery is visible in panel b. The ductal arch in both cases is narrow or hypoplastic. The bicaval plane shows the enlargement of the RA and normal venoatrial arrangement.

Fig. 6: Antenatal cases with different types of DORV (a-d). 3D-reconstructed planes showing the complexity of malposition of both great arteries. In all cases, the $3 \mathrm{VT}$ view shows an abnormal parallel course of both outlet vessels arising from the anatomical RV. The spatial arrangement of the aorta is right anterior in panel a (TGA type at 20 gestational weeks), and it is considerably smaller than the main pulmonary artery. This size discrepancy is confirmed in the LVOT and aortic arch cut section views. There is a huge VSD displayed in the $5 \mathrm{CV}$ and LVOT views (noncommitted). The $4 \mathrm{CV}$ view further shows a common atrium and atretic mitral valve but normal cardiac axis. The latter also applies to the cardiac specimens in panel $\mathrm{b}$ and $\mathrm{c}$ (compared to a marked left rotation in panel d). Panels b-d show both vessels located in a side-by-side position, representing the most common anatomic variant of DORV. According to the accompanying VSD, panels $\mathrm{b}$ and d show a doubly committed arrangement of both outlet vessels. Note the extremely small LV with an atretic MV and the diminished size of the main pulmonary artery (3VT, RVOT) in panel d (seen in the $4 \mathrm{CV}, 5 \mathrm{CV}$, and LVOT views).

Fig. 7: Tetralogy of Fallot at 22 weeks of gestation. The 3VT view shows both vessels nearly equal in size with a patent DA, and the $4 \mathrm{CV}$ view appears to be normal (the cardiac axis is slightly left-rotated). There is a perimembraneous VSD with an overriding medially shifted ascending aorta seen in the 5CV and LVOT views. The RVOT and ductal arch views basically show the main pulmonary artery to be smaller than expected.

Fig. 8: Fetus with ToFAPVS at 29 gestational weeks. The complex cardiac anomaly can be depicted in 
its entirety in 8 of 9 diagnostic planes. Nonrestrictive interventricular communication in the membranous septum. The 3VT view is distorted with no arterial duct. The cardiac proportions are altered, and the cardiac axis is left rotated, as seen in the $4 \mathrm{CV}, 5 \mathrm{CV}$ and LVOT views. There is an overriding aorta with a broad aortic root, and, most strikingly, both the LVOT and RVOT planes show a marked bulging of the main and branch pulmonary arteries and a tiny hourglass-like narrowing at the level of the absent pulmonary valve. The ductal arch cannot be properly reconstructed due the absent DA. The aortic arch and the bicaval plane are otherwise normal.

\section{References}

1. Adriaanse BM, van Vugt JM, Haak MC. Three- and four-dimensional ultrasound in fetal echocardiography: an up-to-date overview. J Perinatol. 2016;36(9):685-693.

2. DeVore GR, Falkensammer P, Sklansky MS, Platt LD. Spatio-temporal image correlation (STIC): new technology for evaluation of the fetal heart. Ultrasound Obstet Gynecol. 2003;22(4):380-387.

3. Lloyd DFA, Pushparajah K, Simpson JM, et al. Three-dimensional visualisation of the fetal heart using prenatal MRI with motion-corrected slice-volume registration: a prospective, single-centre cohort study. Lancet. 2019;393(10181):1619-1627.

4. Novaes JY, Zamith MM, Araujo Júnior E, Barreto EQ, Barros FS, Moron AF. Screening of Congenital Heart Diseases by Three-Dimensional Ultrasound Using Spatiotemporal Image Correlation: Influence of Professional Experience. Echocardiography. 2016;33(1):99-104.

5. Yeo L, Romero R. Fetal Intelligent Navigation Echocardiography (FINE): a novel method for rapid, simple, and automatic examination of the fetal heart. Ultrasound Obstet Gynecol. 2013;42(3):268-284.

6. Yeo L, Luewan S, Romero R. Fetal Intelligent Navigation Echocardiography (FINE) Detects $98 \%$ of Congenital Heart Disease.J Ultrasound Med. 2018;37(11):2577-2593.

7. Straub L, Huybrechts KF, Bateman BT, et al. The Impact of Technology on the Diagnosis of Congenital Malformations. Am J Epidemiol.2019;188(11):1892-1901.

8. Bakker MK, Bergman JEH, Krikov S, et al. Prenatal diagnosis and prevalence of critical congenital heart defects: an international retrospective cohort study. BMJ Open. 2019;9(7):e028139.

9. Evans W, Castillo W, Rollins R, et al. Moving towards universal prenatal detection of critical congenital heart disease in southern Nevada: a community-wide program. Pediatr Cardiol.2015;36(2):281-288.

10. Hautala J, Gissler M, Ritvanen A, et al. The implementation of a nationwide anomaly screening programme improves prenatal detection of major cardiac defects: an 11-year national population-based cohort study. Bjog. 2019;126(7):864-873.

11. Quartermain MD, Pasquali SK, Hill KD, et al. Variation in Prenatal Diagnosis of Congenital Heart Disease in Infants. Pediatrics.2015;136(2):e378-385.

12. Pinto NM, Keenan HT, Minich LL, Puchalski MD, Heywood M, Botto LD. Barriers to prenatal detection of congenital heart disease: a population-based study. Ultrasound Obstet Gynecol.2012;40(4):418-425.

13. Friedberg MK, Silverman NH, Moon-Grady AJ, et al. Prenatal detection of congenital heart disease. $J$ Pediatr. 2009;155(1):26-31, 31.e21.

14. van Velzen CL, Ket JCF, van de Ven PM, Blom NA, Haak MC. Systematic review and meta-analysis of the performance of second-trimester screening for prenatal detection of congenital heart defects. Int $J$ Gynaecol Obstet. 2018;140(2):137-145.

15. Hunter LE, Simpson JM. Prenatal screening for structural congenital heart disease. Nat Rev Cardiol. 2014;11(6):323-334. 
16. Sklansky M, DeVore GR. Fetal Cardiac Screening: What Are We (and Our Guidelines) Doing Wrong? J Ultrasound Med. 2016;35(4):679-681.

17. Fratto VM, Chang A, Anton T, Sun HY, Lamale-Smith LM, Pretorius DH. Detailed Fetal Anatomic Ultrasound Examination: Effect of the 2014 Consensus Report on a Tertiary Referral Center. Ultrasound Q.2019;35(1):21-29.

18. Sun HY, Proudfoot JA, McCandless RT. Prenatal detection of critical cardiac outflow tract anomalies remains suboptimal despite revised obstetrical imaging guidelines. Congenit Heart Dis.2018;13(5):748-756.

19. van Nisselrooij AEL, Teunissen AKK, Clur SA, et al. Why are congenital heart defects being missed? Ultrasound Obstet Gynecol.2020;55(6):747-757.

20. Teitel D. Recognition of Undiagnosed Neonatal Heart Disease. Clin Perinatol. 2016;43(1):81-98.

21. Rigolin VH, Robiolio PA, Wilson JS, Harrison JK, Bashore TM. The forgotten chamber: the importance of the right ventricle. Cathet Cardiovasc Diagn. 1995;35(1):18-28.

22. Kenny JF, Plappert T, Doubilet P, et al. Changes in intracardiac blood flow velocities and right and left ventricular stroke volumes with gestational age in the normal human fetus: a prospective Doppler echocardiographic study. Circulation. 1986;74(6):1208-1216.

23. Roche SL, Redington AN. The failing right ventricle in congenital heart disease. Can J Cardiol. 2013;29(7):768-778.

24. Sheehan F, Redington A. The right ventricle: anatomy, physiology and clinical imaging. Heart. 2008;94(11):1510-1515.

25. Haddad F, Hunt SA, Rosenthal DN, Murphy DJ. Right ventricular function in cardiovascular disease, part I: Anatomy, physiology, aging, and functional assessment of the right ventricle. Circulation.2008;117(11):1436-1448.

26. Ho SY, Nihoyannopoulos P. Anatomy, echocardiography, and normal right ventricular dimensions. Heart. 2006;92 Suppl 1(Suppl 1):i2-13.

27. Sutton MS, Gill T, Plappert T, Saltzman DH, Doubilet P. Assessment of right and left ventricular function in terms of force development with gestational age in the normal human fetus. Br Heart J.1991;66(4):285-289.

28. Hopkins WE. Right ventricular performance in congenital heart disease: a physiologic and pathophysiologic perspective. Cardiol Clin. 2012;30(2):205-218.

29. Goor DA, Lillehei, C.W. Congenital malformations of the heart. In: Goor DA, Lillehei, C.W., ed. Congenital Malformations of the Heart: Embryology, Anatomy, and Operative Considerations. 1st ed. New York: Grune \& Stratton; 1975:1-37.

30. Ebstein W. Ueber einen sehr seltenen Fall von Insufficienz der Valvula tricuspidalis, bedingt durch eine angeborene hochgradige Missbildung derselben. . Arch Anat Physiol. 1866;7:238-254.

31. van Son JA, Konstantinov IE, Zimmermann V. Wilhelm Ebstein and Ebstein's malformation. Eur $J$ Cardiothorac Surg.2001;20(5):1082-1085.

32. Booker OJ, Nanda NC. Echocardiographic assessment of Ebstein's anomaly. Echocardiography. 2015;32 Suppl 2:S177-188.

33. Flores Arizmendi A, Fernández Pineda L, Quero Jiménez C, et al. The clinical profile of Ebstein's malformation as seen from the fetus to the adult in 52 patients. Cardiol Young. 2004;14(1):55-63.

34. Anderson RH. Understanding Ebstein's malformation. Cardiol Young. 2015;25(1):137-138. 
35. Kim MJ, Yu JJ, Kang SY, et al. Comparison of the offset distance of the tricuspid septal leaflet in neonates with Ebstein's anomaly and neonates with pulmonary atresia with intact ventricular septum. Cardiol Young. 2015;25(1):129-136.

36. Shiina A, Seward JB, Edwards WD, Hagler DJ, Tajik AJ. Two-dimensional echocardiographic spectrum of Ebstein's anomaly: detailed anatomic assessment. J Am Coll Cardiol. 1984;3(2 Pt 1):356-370.

37. Dearani JA, Mora BN, Nelson TJ, Haile DT, O'Leary PW. Ebstein anomaly review: what's now, what's next? Expert Rev Cardiovasc Ther. 2015;13(10):1101-1109.

38. Bharucha T, Anderson RH, Lim ZS, Vettukattil JJ. Multiplanar review of three-dimensional echocardiography gives new insights into the morphology of Ebstein's malformation. Cardiol Young.2010;20(1):49-53.

39. Vettukattil JJ, Bharucha T, Anderson RH. Defining Ebstein's malformation using three-dimensional echocardiography. Interact Cardiovasc Thorac Surg. 2007;6(6):685-690.

40. Gottschalk I, Gottschalk L, Stressig R, et al. Ebstein's Anomaly of the Tricuspid Valve in the Fetus A Multicenter Experience. Ultraschall Med. 2017;38(4):427-436.

41. Celermajer DS, Cullen S, Sullivan ID, Spiegelhalter DJ, Wyse RK, Deanfield JE. Outcome in neonates with Ebstein's anomaly. J Am Coll Cardiol. 1992;19(5):1041-1046.

42. Selamet Tierney ES, McElhinney DB, Freud LR, et al. Assessment of Progressive Pathophysiology After Early Prenatal Diagnosis of the Ebstein Anomaly or Tricuspid Valve Dysplasia. Am J Cardiol.2017;119(1):106-111.

43. Wertaschnigg D, Manlhiot C, Jaeggi M, et al. Contemporary Outcomes and Factors Associated With Mortality After a Fetal or Neonatal Diagnosis of Ebstein Anomaly and Tricuspid Valve Disease. Can $J$ Cardiol. 2016;32(12):1500-1506.

44. Freud LR, Escobar-Diaz MC, Kalish BT, et al. Outcomes and Predictors of Perinatal Mortality in Fetuses With Ebstein Anomaly or Tricuspid Valve Dysplasia in the Current Era: A Multicenter Study.Circulation. 2015;132(6):481-489.

45. Eckersley LG, Howley LW, van der Velde ME, et al. Quantitative Assessment of Left Ventricular Dysfunction in Fetal Ebstein's Anomaly and Tricuspid Valve Dysplasia. J Am Soc Echocardiogr.2019;32(12):15981607 .

46. Lasa JJ, Tian ZY, Guo R, Rychik J. Perinatal course of Ebstein's anomaly and tricuspid valve dysplasia in the fetus. Prenat Diagn.2012;32(3):245-251.

47. Tegnander E, Williams W, Johansen OJ, Blaas HG, Eik-Nes SH. Prenatal detection of heart defects in a non-selected population of 30,149 fetuses-detection rates and outcome. Ultrasound Obstet Gynecol. 2006;27(3):252-265.

48. Kreysig FL. Die Krankheiten des Herzens: systematisch bearbeitet und durch eigne Beobachtungen erläutert. Berlin1817.

49. Berg C, Lachmann R, Kaiser C, et al. Prenatal diagnosis of tricuspid atresia: intrauterine course and outcome. Ultrasound Obstet Gynecol. 2010;35(2):183-190.

50. Kühne M. Über zwei Fälle kongenitaler Atresie des Ostium venosum dextrum. In: Jahresbuch Kinderheilkunde. Vol 63.1906:225.

51. Rao PS. A unified classification for tricuspid atresia. Am Heart J. 1980;99(6):799-804.

52. Wald RM, Tham EB, McCrindle BW, et al. Outcome after prenatal diagnosis of tricuspid atresia: a multicenter experience. Am Heart J. 2007;153(5):772-778. 
53. Arya B, Krishnan A, Donofrio MT. Clinical utility of ductus venosus flow in fetuses with right-sided congenital heart disease. J Ultrasound Med. 2014;33(9):1563-1571.

54. Bronshtein M, Blumenfeld Z, Khoury A, Gover A. Diverse outcome following early prenatal diagnosis of pulmonary stenosis. Ultrasound Obstet Gynecol. 2017;49(2):213-218.

55. Grech V. History, diagnosis, surgery and epidemiology of pulmonary stenosis in Malta. Cardiol Young. 1998;8(3):337-343.

56. Guirado L, Crispi F, Masoller N, et al. Biventricular impact of mild to moderate fetal pulmonary valve stenosis. Ultrasound Obstet Gynecol. 2018;51(3):349-356.

57. Jarcho S. Pulmonic stenosis with patent interatrial septum (Morgagni, 1761). Am J Cardiol. 1958;1(1):132-133.

58. Morgagni G. de Morbis Thoracis, Epistola XVIII. In: De sedibus et causis morborum. Venetia; 1761:154.

59. Castor S, Fouron JC, Teyssier G, Sonnesson SE, Chartrand C, Skoll A. Assessment of fetal pulmonic stenosis by ultrasonography. J Am Soc Echocardiogr. 1996;9(6):805-813.

60. Lindqvist P, Calcutteea A, Henein M. Echocardiography in the assessment of right heart function. Eur $J$ Echocardiogr.2008;9(2):225-234.

61. Gardiner HM, Belmar C, Tulzer G, et al. Morphologic and functional predictors of eventual circulation in the fetus with pulmonary atresia or critical pulmonary stenosis with intact septum. J Am Coll Cardiol. 2008;51(13):1299-1308.

62. Gottschalk I, Strizek B, Menzel T, et al. Severe Pulmonary Stenosis or Atresia with Intact Ventricular Septum in the Fetus: The Natural History. Fetal Diagn Ther. 2020;47(5):420-428.

63. Freedom RM, Nykanen, D. G. Pulmonary Atresia and Intact Ventricular Septum. In: Emmanouilides GC AH, Riemenschneider TD, Gutgesell HP, ed.Moss and Adams' Heart Disease in Infants, Children, and Adolescents. 7th ed.: Lippincott Williams \& Wilkins; 2008:488-497.

64. Roman KS, Fouron JC, Nii M, Smallhorn JF, Chaturvedi R, Jaeggi ET. Determinants of outcome in fetal pulmonary valve stenosis or atresia with intact ventricular septum. Am J Cardiol. 2007;99(5):699-703.

65. Iacobelli R, Pasquini L, Toscano A, et al. Role of tricuspid regurgitation in fetal echocardiographic diagnosis of pulmonary atresia with intact ventricular septum. Ultrasound Obstet Gynecol.2008;32(1):31-35.

66. Vierordt H. Die angeborenen Herzkrankheiten. In: Nothnagel H, ed.Specielle Pathologie und Therapie. Vol XV. Wien: Hölder, A.; 1898.

67. Taussig HB, Bing RJ. Complete transposition of the aorta and a levoposition of the pulmonary artery; clinical, physiological, and pathological findings. Am Heart J. 1949;37(4):551-559.

68. Lev M, Bharati S, Meng CC, Liberthson RR, Paul MH, Idriss F. A concept of double-outlet right ventricle. J Thorac Cardiovasc Surg. 1972;64(2):271-281.

69. Neufeld HN, Lucas RV, Jr., Lester RG, Adams P, Jr., Anderson RC, Edwards JE. Origin of both great vessels from the right ventricle without pulmonary stenosis. Br Heart J. 1962;24(4):393-408.

70. Obler D, Juraszek AL, Smoot LB, Natowicz MR. Double outlet right ventricle: aetiologies and associations. J Med Genet.2008;45(8):481-497.

71. Walters HL, 3rd, Mavroudis C, Tchervenkov CI, Jacobs JP, Lacour-Gayet F, Jacobs ML. Congenital Heart Surgery Nomenclature and Database Project: double outlet right ventricle. Ann Thorac Surg.2000;69(4 Suppl):S249-263.

72. Witham AC. Double outlet right ventricle; a partial transposition complex. Am Heart J. 1957;53(6):928939. 
73. Lacour-Gayet F. Intracardiac repair of double outlet right ventricle. Semin Thorac Cardiovasc Surg Pediatr Card Surg Annu.2008:39-43.

74. Gelehrter S, Owens ST, Russell MW, van der Velde ME, Gomez-Fifer C. Accuracy of the fetal echocardiogram in double-outlet right ventricle. Congenit Heart Dis. 2007;2(1):32-37.

75. Gottschalk I, Abel JS, Menzel T, et al. Prenatal diagnosis, associated findings and postnatal outcome of fetuses with double outlet right ventricle (DORV) in a single center. $J$ Perinat Med.2019;47(3):354-364.

76. Kim N, Friedberg MK, Silverman NH. Diagnosis and prognosis of fetuses with double outlet right ventricle. Prenat Diagn.2006;26(8):740-745.

77. Gedikbasi A, Oztarhan K, Gul A, Sargin A, Ceylan Y. Diagnosis and prognosis in double-outlet right ventricle. Am J Perinatol.2008;25(7):427-434.

78. Hartge DR, Niemeyer L, Axt-Fliedner R, et al. Prenatal detection and postnatal management of double outlet right ventricle (DORV) in 21 singleton pregnancies. J Matern Fetal Neonatal Med.2012;25(1):58-63.

79. Zidere V, Pushparajah K, Allan LD, Simpson JM. Three-dimensional fetal echocardiography for prediction of postnatal surgical approach in double outlet right ventricle: a pilot study. Ultrasound Obstet Gynecol. 2013;42(4):421-425.

80. Lagopoulos ME, Manlhiot C, McCrindle BW, Jaeggi ET, Friedberg MK, Nield LE. Impact of prenatal diagnosis and anatomical subtype on outcome in double outlet right ventricle. Am Heart J.2010;160(4):692700 .

81. Bailliard F, Anderson RH. Tetralogy of Fallot. Orphanet J Rare Dis. 2009;4:2.

82. Montealegre-Gallegos M, Mahmood F. La Maladie Bleue (the Blue Disease) in the 21st Century: Do We Need a New Specialty? J Cardiothorac Vasc Anesth. 2015;29(5):1396-1397.

83. Acierno LJ. Etienne-Louis Fallot: is it his tetralogy? Clin Cardiol. 1999;22(4):321-322.

84. Steno N. Anatomicus regij Hafniensis Embryo Monstro affinis Parisiis dissectus. Acta Med Et Philosophia Hafmiensia. 1671;1:200-205.

85. Zhao Y, Abuhamad A, Fleenor J, et al. Prenatal and Postnatal Survival of Fetal Tetralogy of Fallot: A Meta-analysis of Perinatal Outcomes and Associated Genetic Disorders. J Ultrasound Med.2016;35(5):905915.

86. Yeo L, Markush D, Romero R. Prenatal diagnosis of tetralogy of Fallot with pulmonary atresia using: Fetal Intelligent Navigation Echocardiography (FINE). J Matern Fetal Neonatal Med.2019;32(21):3699-3702.

87. Zhao Y, Edington S, Fleenor J, Sinkovskaya E, Porche L, Abuhamad A. Fetal cardiac axis in tetralogy of Fallot: associations with prenatal findings, genetic anomalies and postnatal outcome. Ultrasound Obstet Gynecol. 2017;50(1):58-62.

88. Peng R, Zheng J, Xie HN, He M, Lin MF. Genetic anomalies in fetuses with tetralogy of Fallot by using high-definition chromosomal microarray analysis. Cardiovasc Ultrasound. 2019;17(1):8.

89. Lv J, Yang T, Gu X, et al. Differential diagnosis of fetal large ventricular septal defect and tetralogy of Fallot based on big data analysis. Echocardiography. 2020;37(4):620-624.

90. Wu LH, Wang N, Xie HN, Du L, Peng R. Cardiovascular Z-scores in fetuses with tetralogy of Fallot. Ultrasound Obstet Gynecol.2014;44(6):674-681.

91. Rodenbarger A, Thorsson T, Stiver C, et al. Third trimester predictors of interventional timing and accuracy of fetal anticipatory guidance in tetralogy of Fallot: A multi-center study. Prenat Diagn. 2020;40(7):870877.

92. Crampton J. Case of an anomalous state of the heart. Dub Med Trans NS. 1830;1:34. 
93. D'Cruz IA, Miller RA. Norman Chevers. A Description of congenital abscence of pulmonary valves and supravalvular aortic stenosis in the 1840's Br Heart J. 1964;26(6):723-725.

94. Chevers N. A collection of facts illustrative of the morbid conditions of the pulmonary artery, as bearing upon the treatment of cardiac and pulmonary diseases. London Medical Gazette.1846;38:189, 276, 369, 452, $699,744,828,961,1087$.

95. Miller RA, Lev M, Paul MH. Congenital absence of the pulmonary valve. The clinical syndrome of tetralogy of Fallot with pulmonary regurgitation. Circulation. 1962;26:266-278.

96. Galindo A, Gutiérrez-Larraya F, Martínez JM, et al. Prenatal diagnosis and outcome for fetuses with congenital absence of the pulmonary valve. Ultrasound Obstet Gynecol. 2006;28(1):32-39.

97. Volpe P, Paladini D, Marasini M, et al. Characteristics, associations and outcome of absent pulmonary valve syndrome in the fetus. Ultrasound Obstet Gynecol. 2004;24(6):623-628.

98. Axt-Fliedner R, Kurkevych A, Slodki M, et al. Absent pulmonary valve syndrome - diagnosis, associations, and outcome in 71 prenatally diagnosed cases. Prenat Diagn. 2017;37(8):812-819.

99. Gottschalk I, Jehle C, Herberg U, et al. Prenatal diagnosis of absent pulmonary valve syndrome from first trimester onwards: novel insights into pathophysiology, associated conditions and outcome. Ultrasound Obstet Gynecol. 2017;49(5):637-642.

100. Berg C, Thomsen Y, Geipel A, Germer U, Gembruch U. Reversed end-diastolic flow in the umbilical artery at 10-14 weeks of gestation is associated with absent pulmonary valve syndrome. Ultrasound Obstet Gynecol. 2007;30(3):254-258.

101. Pinsky WW, Nihill MR, Mullins CE, Harrison G, McNamara DG. The absent pulmonary valve syndrome. Considerations of management. Circulation. 1978;57(1):159-162.

102. Hartge D, Hoffmann U, Schröer A, Weichert J. Three- and four-dimensional ultrasound in the diagnosis of fetal tetralogy of fallot with absent pulmonary valve and microdeletion 22q11.Pediatr Cardiol. 2010;31(7):1100-1103.

103. Jegatheeswaran A, Oliveira C, Batsos C, et al. Costs of prenatal detection of congenital heart disease. Am J Cardiol.2011;108(12):1808-1814.

104. Espinoza J, Lee W, Comstock C, et al. Collaborative study on 4-dimensional echocardiography for the diagnosis of fetal heart defects: the COFEHD study. J Ultrasound Med. 2010;29(11):1573-1580.

105. Li Y, Hua Y, Fang J, et al. Performance of different scan protocols of fetal echocardiography in the diagnosis of fetal congenital heart disease: a systematic review and meta-analysis. PLoS One.2013;8(6):e65484.

106. Yagel S, Cohen SM, Rosenak D, et al. Added value of three-/four-dimensional ultrasound in offline analysis and diagnosis of congenital heart disease. Ultrasound Obstet Gynecol.2011;37(4):432-437.

107. Jaudi S, Fries N, Tezenas du Montcel S, Dommergues M. The impact of insonation angle on four-chamber view image quality: an observational study on 2866 routine scans. Prenat Diagn. 2015;35(4):382-385.

108. Yeo L, Romero R. How to Acquire Cardiac Volumes for Sonographic Examination of the Fetal Heart: Part 2. J Ultrasound Med.2016;35(5):1043-1066.

109. Yeo L, Romero R. How to Acquire Cardiac Volumes for Sonographic Examination of the Fetal Heart: Part 1. J Ultrasound Med.2016;35(5):1021-1042. 

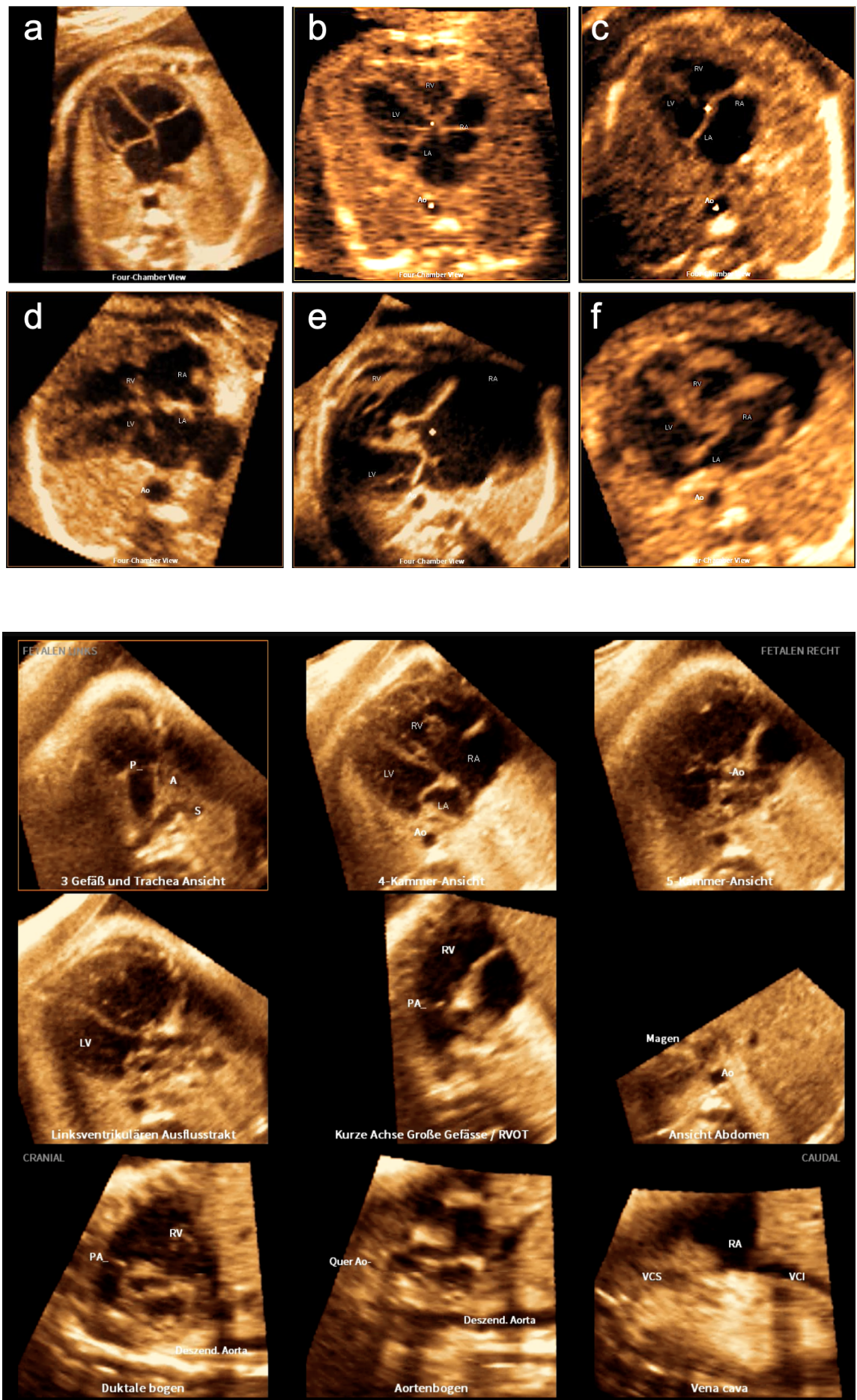

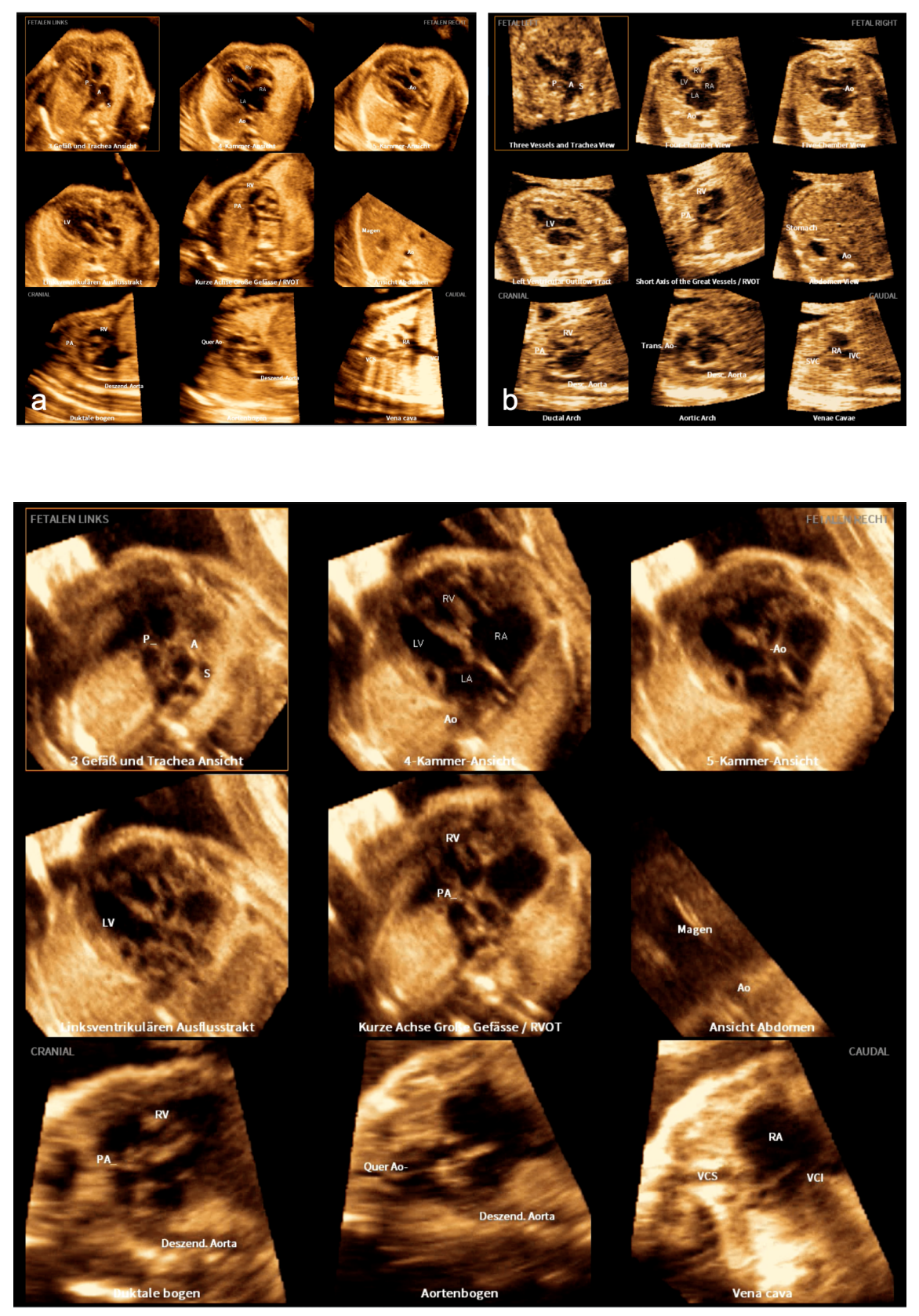

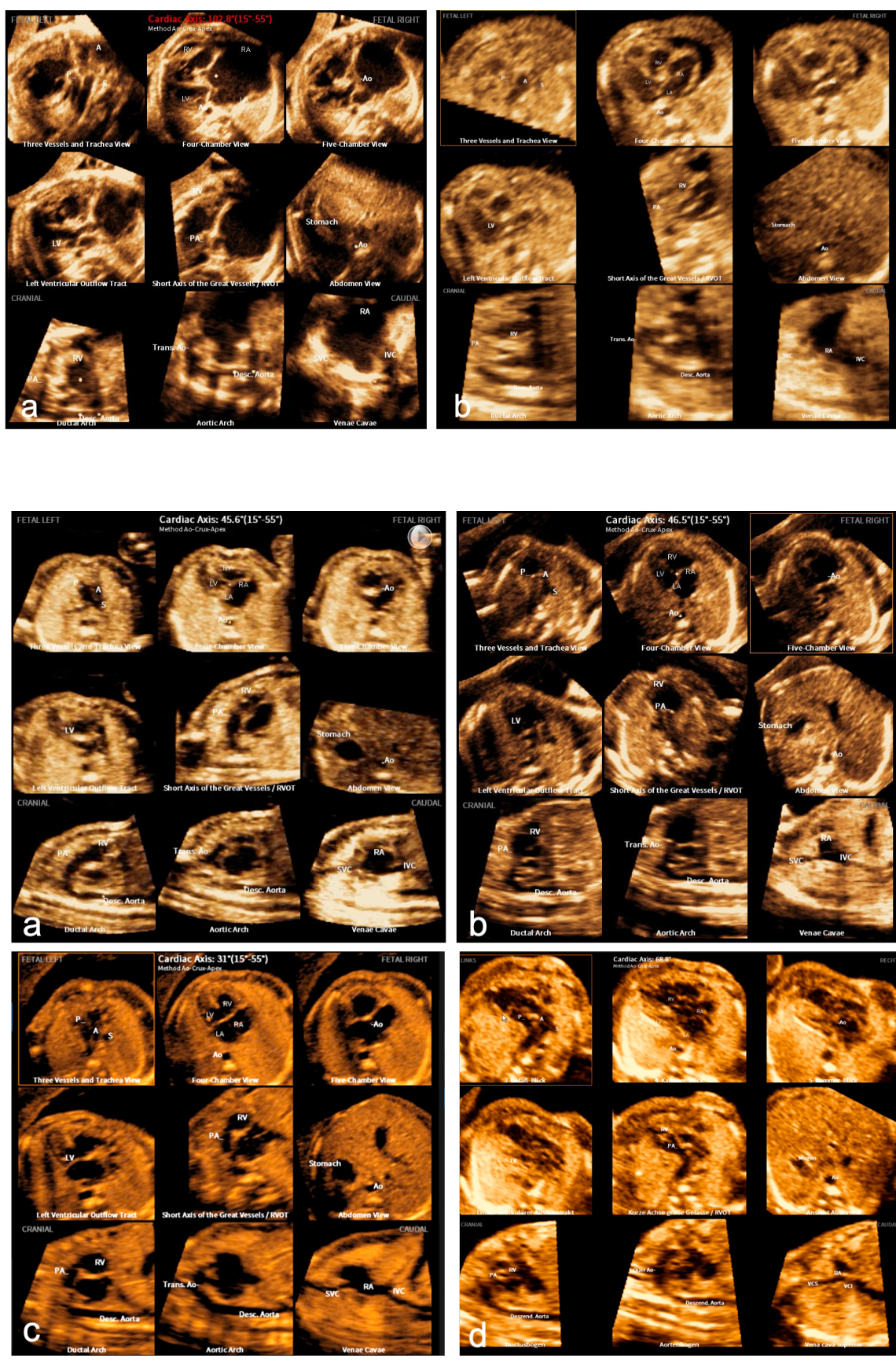


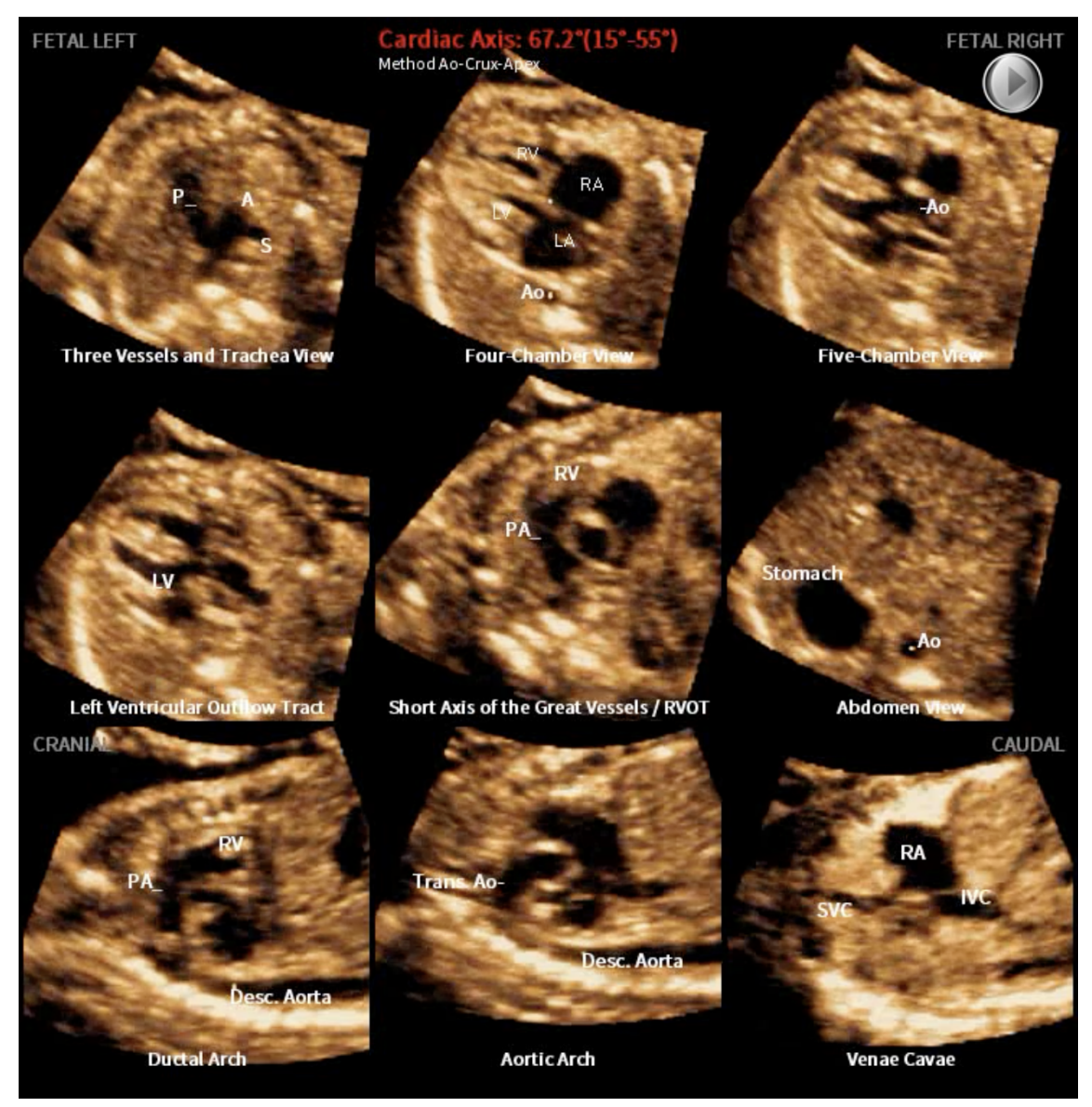




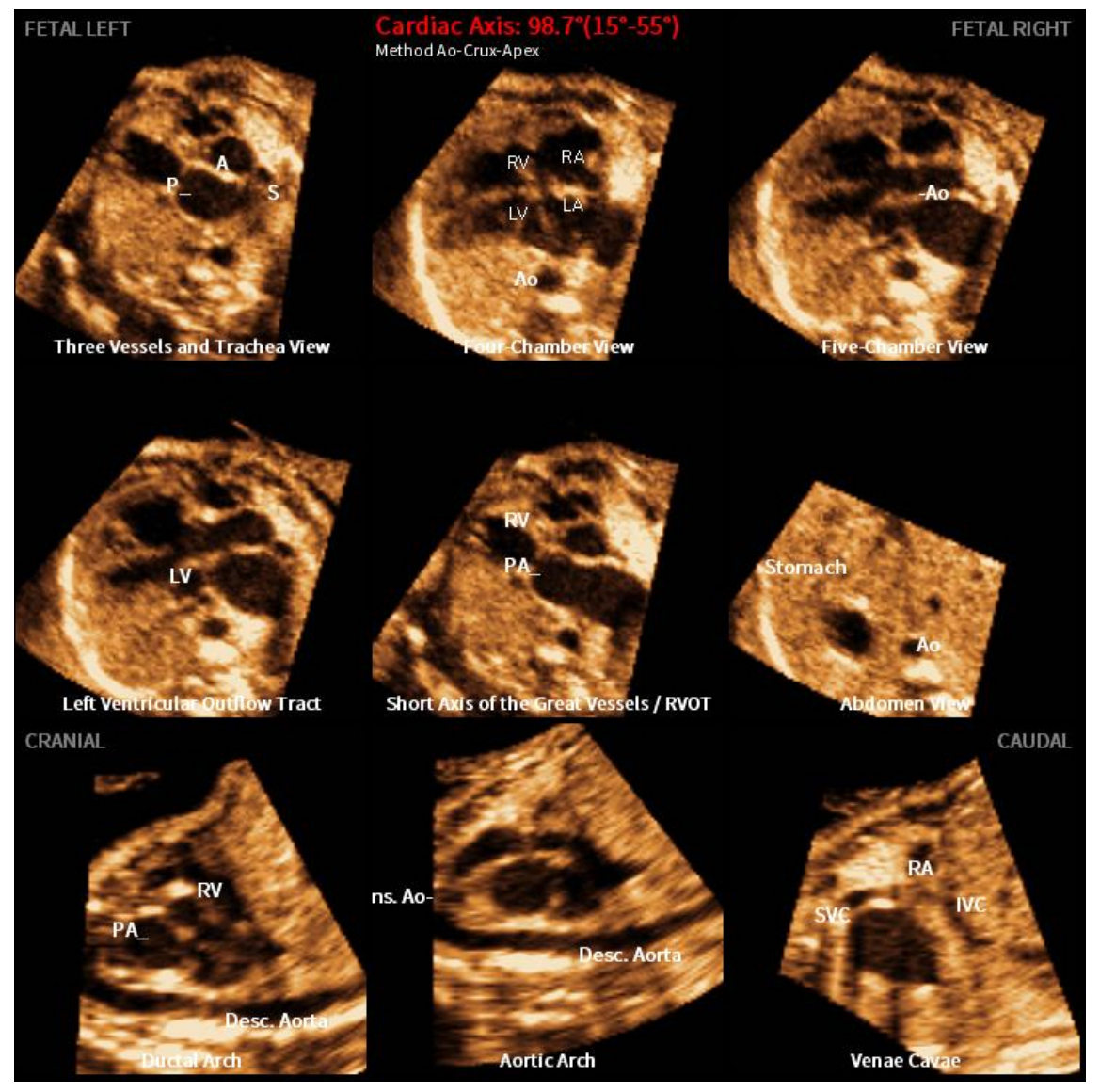

